\title{
Making the Most of What We Have: A Framework for Preservation Management in Rare Book Collections
}

WE ARE FACING AN UNCERTAIN FUTURE in special collections-one that will most likely continue to require us to make tough decisions. With cutbacks and limitations on resources plaguing us, the expense and time required for item-level treatment make it necessary to set preservation priorities within our collections. ${ }^{1}$ At the same time, digital initiatives continue to expand in scope and resource allocation, creating new opportunities and challenges in preservation management. Digitization has a valuable place in special collections as a supplement to physical preservation, but the danger arises when the digital begins to supplant the physical.

So we need to ask ourselves_-in rare book collections, what exactly are we trying to preserve? Do we maintain the physical object, or do we risk losing the information retained in its inherent characteristics? When the "form" and "substance" of a given object are indistinguishable, ${ }^{2}$ we are challenged to evaluate collection materials in terms of their inherent value, which includes both the text and the intangible information the materials provide.

The literature addresses the need for preservation priorities ${ }^{3}$ and offers some subjective criteria that could be used for making such decisions, ${ }^{4}$ but it is time to take the next step in establishing guidelines for setting preservation priorities. A need exists for a standardized and objective decision-making framework to guide itemlevel preservation and conservation activities in rare book collections. The presence of a standard could assist in justifying the use of limited resources for executing preservation decisions. I am presenting the following framework as one such tem-

1. Pauline Kamel, “Conservation Treatment of Rare Books,” Feliciter 45.2 (1999): 108-12.

2. Michèle Valerie Cloonan, "W(h)ither Preservation?” Library Quarterly 71.2 (2001): 231-42.

3. John Feather, Preservation and the Management of Library Collections (London: The Library Association, 1991); Nancy E. Gwinn, “The Fragility of Paper: Can Our Historical Record Be Saved?” The Public Historian 13.3 (summer 1991): 33-53; Tyler O. Walters, "Contemporary Archival Appraisal Methods and Preservation Decision-Making,” American Archivist 59.3 (1996): 322-38.

4. Anthony W. Ferguson, "Preservation Decision-Making Basics: A University Library Collection Developer's Perspective,” Acquisitions Librarian 2 (1989): 239-46. 
plate-one that takes into consideration many of the characteristics that contribute to the inherent value of an object.

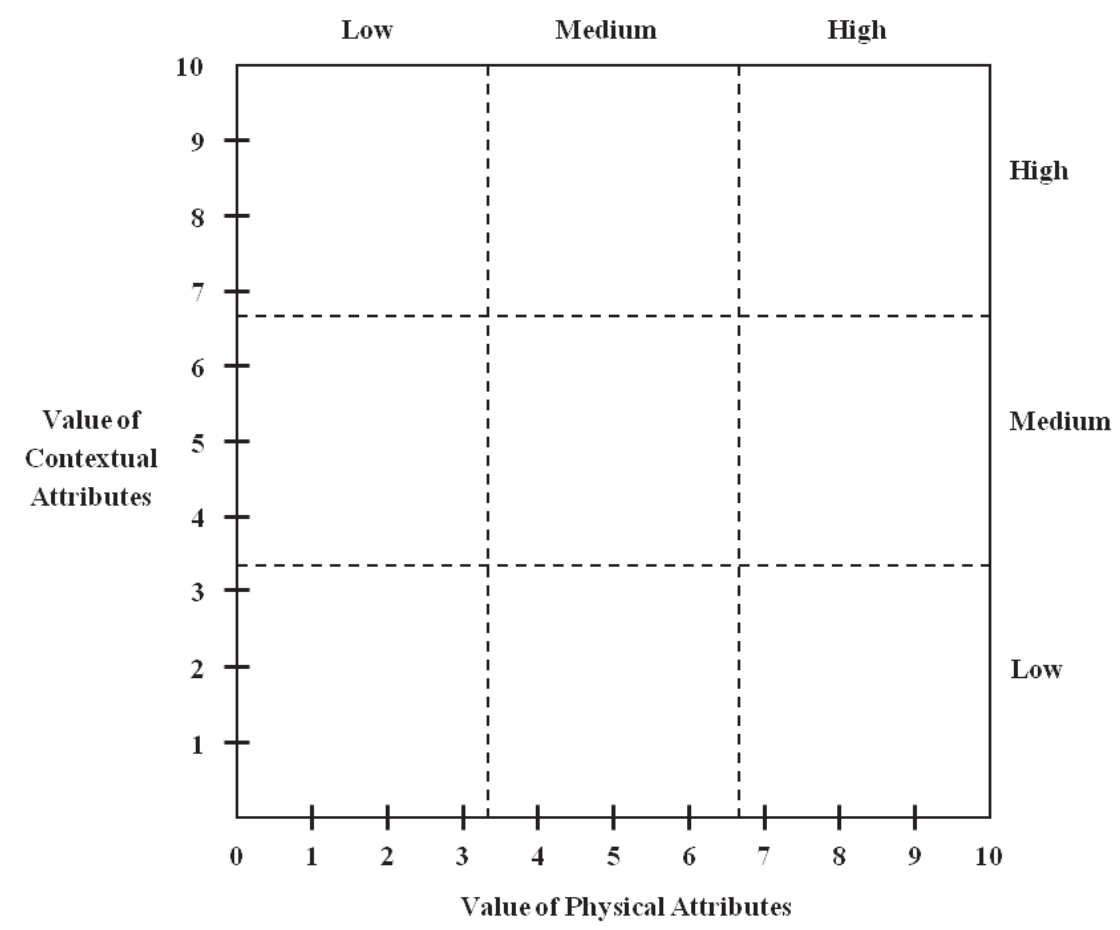

Figure 1. Framework for preservation decision-making in rare book collections, incorporating attributes relating to physicality and context.

Using this framework, a given book receives a data point based upon its cumulative score for seven physical and seven contextual attributes. The seven physical attributes that are scored are: authenticity, condition, aesthetic value, special features, binding, textual variants, and value of materials, and the seven contextual attributes are: historical value, cultural value, provenance, availability, demand, production, and association.

\section{Developing the Framework}

The process by which I devised those two lists began by reviewing the literature and compiling an initial list of 13 characteristics that contribute to the "value" of rare books. ${ }^{5}$ The characteristics were: authenticity, association, textual variants,

5. Kenneth Lavender, What Makes a Rare Book Rare? (Denton, Tex.: University of North Texas, 2003); Alice Schreyer, "Common Cause: Collaborating to Preserve Printed and Primary Source Materials," in Getting Ready for the 19th Century: Strategies and Solutions for Rare Books and Special Collections Librarians, eds. William E. Brown, Jr. and Laura Stalker (Chicago: Association of College and Research Libraries, American Library Association, 2000), 34-40; Peter Van Wingen, Your Old Books (Chicago: Rare Books and Manuscripts Section, Association of College and Research Libraries, American Library Association), available online at www.rbms.info/yob.shtml. 
production, cultural value, historical value, aesthetic value, provenance, binding, condition, demand, availability, and special features. To this list, I added a 14th: the monetary value of the materials used in the construction of the book.

In searching for participants in the study, I cast a fairly wide net. I explored a list of universities within the state of Texas ${ }^{6}$ and studied their Web sites to find institutions with special collections containing rare books; archives were not included. Then I conducted an Internet search for rare book collections to find participants outside the state. I contacted administrators at 17 different collections, and I received a surprisingly low response, with only six agreeing to participate. I would like to try the project again in the future with a larger sample, because I know that the small size could present limitations in my results. Nonetheless, the overall concepts in the creation of the framework remain valid. The six participants represent collections at large and small, public and private academic libraries, so I felt that their responses could still be quite useful for my purposes. To those six individuals, I submitted the list of 14 criteria. No formal definitions were provided for each term because I wanted responses that would reflect each person's professional and educational experiences.

They were asked to rank the 14 characteristics on a scale of 1-14, with 1 indicating the term of greatest importance to the value of a book, and 14 indicating least importance. I then asked them to determine if they felt that any criteria were absent from the list and to indicate if any of the included criteria should be removed. Also, if they believed that any of the terminology should be changed, I gave them an opportunity to indicate those recommendations.

Table 1 on the following page illustrates the rankings they assigned.

Only one of the participants indicated any additions or deletions. He suggested that research value should be added, and value of materials should be removed because "one could take a perfectly ordinary book and deck it out with gold and gems and still not have a rare book, merely an expensive ordinary book." After contemplating his suggestion, I ultimately decided not to include research value. I felt that the research value of a rare book, in relation to the text, is not incorporated into the book's inherent value as an information-bearing object and could therefore be adequately represented in a surrogate. On the other hand, any research value reflecting the physical characteristics or context of the book can be incorporated into the other 13 criteria. For example, research value based on a notable individual's marginalia could be classified as association.

6. University of Texas, "U.S. Universities by State." Available online at www.utexas.edu/world/ univ/state/\#TX. 
Table 1 Rankings of 14 criteria which may be attributed to rare books

\begin{tabular}{lrrrrrr}
\hline & $\begin{array}{r}\text { Expert } \\
\text { One }\end{array}$ & $\begin{array}{r}\text { Expert } \\
\text { Two }\end{array}$ & $\begin{array}{r}\text { Expert } \\
\text { Three }\end{array}$ & $\begin{array}{r}\text { Expert } \\
\text { Four }\end{array}$ & $\begin{array}{r}\text { Expert } \\
\text { Five }\end{array}$ & $\begin{array}{r}\text { Expert } \\
\text { Six }\end{array}$ \\
\hline Authenticity & 1 & 1 & 7 & 1 & 11 & 1 \\
Association & 10 & 6 & 12 & 8 & 9 & 14 \\
Textual Variants & 7 & 8 & 13 & 9 & 3 & 6 \\
Cultural Value & 6 & 4 & 2 & 2 & 5 & 7 \\
Historical Value & 5 & 3 & 1 & 3 & 6 & 2 \\
Provenance & 3 & 7 & 11 & 4 & 10 & 4 \\
Special Features & 12 & 5 & 10 & 10 & 2 & 9 \\
Aesthetic Value & 9 & 13 & 6 & 11 & 4 & 8 \\
Production & 8 & 12 & 8 & 14 & 8 & 13 \\
Demand & 13 & 9 & 3 & 12 & 13 & 11 \\
Availability & 4 & 14 & 4 & 13 & 14 & 12 \\
Condition & 2 & 2 & 5 & 5 & 1 & 5 \\
Binding & 11 & 11 & 9 & 7 & 7 & 10 \\
Value of Materials & 14 & 10 & 14 & 6 & 12 & 3 \\
\hline
\end{tabular}

I also felt that continuing to include value of materials was important. I would argue that many of the books housed in our collections may be "ordinary" books that have been entrusted to us solely because they were constructed of expensive materials. It seems to me that those materials are vital considerations for preservation decisions. Because the responses of the other participants supported my position on both research value and value of materials, I decided to keep the original list of 14 criteria.

After looking at the first table, I realized that the results produced an ordering of the terms but no respective weights relative to each of the characteristics. Therefore, I sent a second question to the same participants. I asked each to respond to the following question regarding the criteria from the first survey:

"Imagine that you have 100 tokens to distribute according to each of the following characteristics. Please distribute these tokens among the 14 characteristics, based on your perception of their respective importance. For example, if authenticity or another given term is highly valued, it would receive a larger portion of those 100 tokens."

After receiving the second set of responses, I constructed table 2.

From this table, I developed a chart to illustrate the distribution of the terms. I arranged the terms to provide an illustration of their descending relative frequencies, 
according to the number of tokens that the group of participants had cumulatively attributed to each characteristic.

Table 2 Allocation of 100 tokens among 14 criteria which may be attributed to rare books

\begin{tabular}{lrrrrrr}
\hline & $\begin{array}{r}\text { Expert } \\
\text { One }\end{array}$ & $\begin{array}{r}\text { Expert } \\
\text { Two }\end{array}$ & $\begin{array}{r}\text { Expert } \\
\text { Three }\end{array}$ & $\begin{array}{r}\text { Expert } \\
\text { Four }\end{array}$ & $\begin{array}{r}\text { Expert } \\
\text { Five }\end{array}$ & $\begin{array}{r}\text { Expert } \\
\text { Six }\end{array}$ \\
\hline Authenticity & 30 & 12 & 3 & 50 & 1 & 14 \\
Association & 0 & 7 & 3 & 5 & 4 & 4 \\
Textual Variants & 0 & 7 & 2 & 1 & 12 & 6 \\
Cultural Value & 10 & 7 & 15 & 4 & 11 & 7 \\
Historical Value & 10 & 7 & 15 & 10 & 11 & 12 \\
Provenance & 10 & 7 & 3 & 5 & 4 & 9 \\
Special Features & 5 & 8 & 3 & 1 & 12 & 5 \\
Aesthetic Value & 5 & 3 & 5 & 10 & 11 & 6 \\
Production & 0 & 6 & 5 & 1 & 9 & 3 \\
Demand & 0 & 6 & 15 & 1 & 0 & 4 \\
Availability & 10 & 5 & 15 & 1 & 0 & 4 \\
Condition & 15 & 12 & 10 & 5 & 15 & 8 \\
Binding & 5 & 7 & 5 & 1 & 10 & 5 \\
Value of Materials & 0 & 6 & 1 & 5 & 0 & 13 \\
\hline
\end{tabular}

Upon examining the 14 criteria, I was pleased and surprised to discover that the set divides easily into two subsets of seven. The first group pertains to the physical object of the book, consisting of authenticity, condition, aesthetic value, special features, binding, textual variants, and value of materials. The other set reflects the context in which the book has existed and consists of historical value, cultural value, provenance, availability, demand, production, and association.

Within these two categories, I wanted to establish specific weights for each term, so I gave each term its cumulative number of tokens from the second survey, reflected in figure 1 , and divided that cumulative score by the sum of the scores for all seven criteria in the given category. For example, authenticity received a total of 110 tokens from all
Table 3 Percentage weights for physical characteristics of rare books

\begin{tabular}{|c|c|c|c|}
\hline $\begin{array}{c}\text { Physical } \\
\text { Characteristic }\end{array}$ & & $\begin{array}{r}\text { Total Number } \\
\text { of Tokens }\end{array}$ & $\begin{array}{r}\text { Normalized } \\
\text { Score }\end{array}$ \\
\hline Authenticity & & 110 & 0.328 \\
\hline Condition & & 65 & 0.194 \\
\hline Aesthetic Value & & 40 & 0.119 \\
\hline Special Features & & 34 & 0.101 \\
\hline Binding & & 33 & 0.099 \\
\hline Textual Variants & & 28 & 0.084 \\
\hline \multirow[t]{2}{*}{ Material Value } & & 25 & 0.075 \\
\hline & Total & 335 & 1.000 \\
\hline
\end{tabular}


Importance of Characteristic

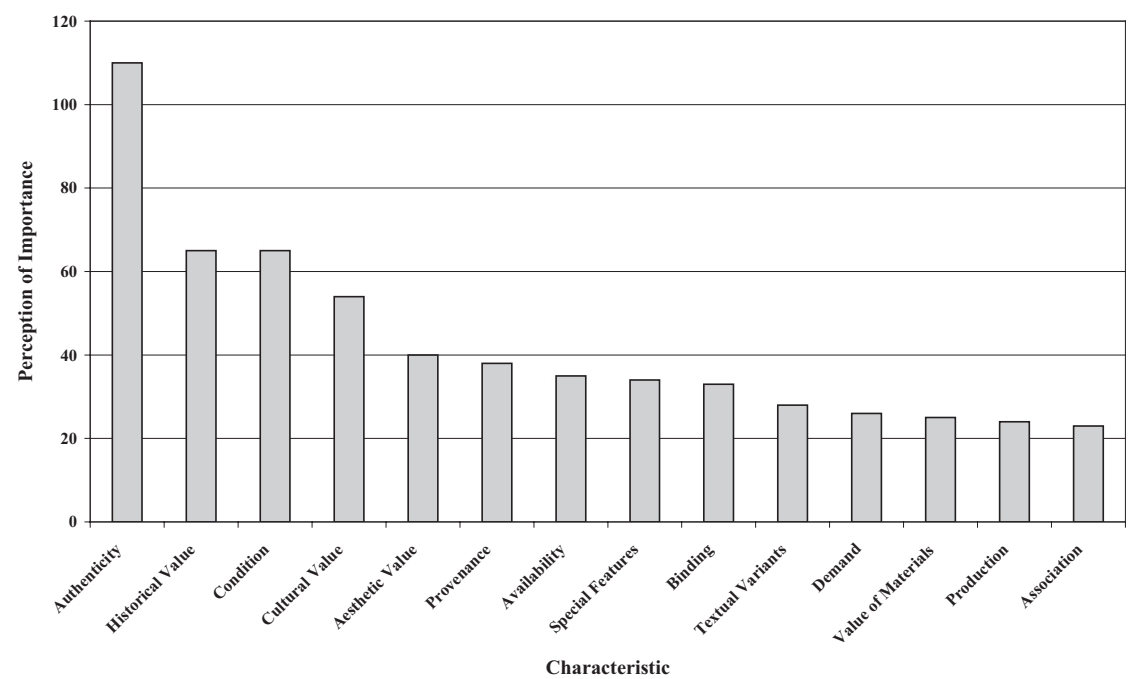

Figure 2. Frequency of distribution for 14 criteria of rare books, based upon allocations of tokens for all participants.

of the participants- the highest number attributed to a physical characteristic. This number was divided by 335 , which was the number of total tokens attributed to the subset of seven physical characteristics, and the resulting normalized score for authenticity was 0.328 .

The next step in the process was to set a zero to ten scale for each criterion. For a given book, the person evaluating it would assign a score for each of the 14 criteria, with zero indicating that the given characteristic is not present, and ten indicating that it is of extremely high importance. Although I recognize

Table 4 Percentage weights for contextual characteristics of rare books

\begin{tabular}{|c|c|c|c|}
\hline $\begin{array}{c}\text { Contextual } \\
\text { Characteristic }\end{array}$ & & $\begin{array}{r}\text { Total Number } \\
\text { of Tokens }\end{array}$ & $\begin{array}{r}\text { Normalized } \\
\text { Score }\end{array}$ \\
\hline Historical Value & & 65 & 0.245 \\
\hline Cultural Value & & 54 & 0.204 \\
\hline Provenance & & 38 & 0.143 \\
\hline Availability & & 35 & 0.132 \\
\hline Demand & & 26 & 0.098 \\
\hline Production & & 24 & 0.091 \\
\hline \multirow[t]{2}{*}{ Association } & & 23 & 0.087 \\
\hline & Total & 265 & 1.000 \\
\hline
\end{tabular}
that assigning values to the characteristics of rare books is subjective, my hope is that confining the process to a scale of zero to ten provides a more quantifiable measurement and reduces the subjectivity to a certain degree.

And this brings us back to figure 1. For each criterion, the normalized weight is multiplied by the zero to ten score for that criterion. This is repeated for all 14 
characteristics. Then the products for the seven physical characteristics are added together to create a coordinate on the horizontal axis of the framework, and the seven contextual characteristics mark a location on the vertical axis. The intersection of those two coordinates creates a data point. The lowest possible score for either dimension is zero, which would indicate that values of zero had been assigned for all of the seven characteristics within that dimension. Similarly, the highest possible score is ten, which would indicate that a value of ten had been attributed to all of the criteria.

To demonstrate the process in more concrete terms, I will use an example from my institution's collection: Lucius Annaeus Seneca's Opera philosophica et epistolae, printed in 1478 in Treviso, Italy, by Bernardinus de Colonia. My first step in applying the framework is to assign scores for each of the 14 criteria to the book. I have also included my rationale for each score:

Authenticity: The British Library's Incunabula Short Title Catalogue lists this copy as one of the extant copies of the work in the United States, ${ }^{7}$ and the associated presumption of authenticity merits a score of 9 .

Condition: The book is in excellent condition, and I would give a score of 8 for this area. It could be argued that because we are setting preservation priorities, items in poorer condition may need higher scores because they are in more immediate need of stabilization. My perspective, however, is that a score of 10 would be given to an item in pristine condition, because the scale is addressing that criterion's contribution to the value of the object, and we can usually assume the better the condition, the higher the value.

Aesthetic Value: The book is bound in a laced-in binding of vellum over boards, undecorated other than a spine title and date in ink. The pages are printed in black ink, rubricated in red and blue. Aesthetically, I would assign a value of 5 .

Special Features: There are no special features (such as maps or illustrations) in the work, so I assigned a value of 0 .

Binding: As I mentioned above, the binding is laced-in vellum over boards and is likely the original binding for the work. The significance of the binding led me to assign a score of 8 for this area.

Textual Variants: The Incunabula Short Title Catalogue (British Library 2009) lists

7. British Library, "Incunabula Short Title Catalogue." Available online at http://istc.bl.uk/search/ search.html?operation $=$ record $\& \mathrm{rsid}=22748 \& \mathrm{q}=30$. 
seven separate printings of this work in the fifteenth century alone, and countless other printings exist. Because of the research value associated with the variants, I assigned a score of 8 .

Value of Materials: Paper and vellum are not particularly expensive materials, and therefore this characteristic received a value of 2 .

Historical Value: Because this book is an incunabulum, the historical value is quite high, and I assigned it a value of 8. A book like a Gutenberg Bible or another of extreme historical significance would receive a higher score.

Cultural Value: The work seemed to merit a score of 8, because the existence of multiple printings of Seneca's works in the late fifteenth century suggests a renewed interest in his writings.

Provenance: The documentation relating to the volume's history of ownership extends to only the previous owner of the work. Therefore, the value for provenance is 2 .

Availability: This printing of the work is fairly uncommon. The Incunabula Short Title Catalogue lists only 28 copies in the United States (British Library 2009). Thus the value for availability is 9 .

Demand: Although this book is not a particularly "hot" item that is actively collected at this time, its availability would suggest a moderate demand for this book. I therefore assigned a value of 6 for this category.

Production: The printing location, date, and the name of "Bernardinus de Colonia" as printer of this work are all available. Because we have this information related to the book's production, I would give this area a score of 9 .

Association: There are marginalia of a later date in the work; but, because we cannot associate these notations with any particular person, I would assign a score of 3 in this area.

Table 5 Physical characteristic scores

\begin{tabular}{|c|c|c|}
\hline Characteristic & Score & $\begin{array}{l}\text { ighted } \\
\text { Score } \\
\end{array}$ \\
\hline Authenticity & $9 \times .328=$ & 2.952 \\
\hline Condition & $8 \times .194=$ & 1.552 \\
\hline Aesthetic Value & $5 \times .119=$ & 0.595 \\
\hline Special Features & $0 \times .101=$ & 0.000 \\
\hline Binding & $8 \times .099=$ & 0.792 \\
\hline Textual Variants & $8 \times .084=$ & 0.672 \\
\hline Material Value & $2 \times .075=$ & 0.150 \\
\hline \multicolumn{2}{|c|}{ Total } & 6.713 \\
\hline
\end{tabular}


Table 6 Contextual characteristic scores

\begin{tabular}{ccr}
\hline Characteristic & Score & $\begin{array}{r}\text { Weighted } \\
\text { Score }\end{array}$ \\
\hline Historical Value & $8 \times .245=$ & 1.960 \\
Cultural Value & $8 \times .204=$ & 1.632 \\
Provenance & $2 \times .143=$ & 0.286 \\
Availability & $9 \times .132=$ & 1.188 \\
Demand & $6 \times .098=$ & 0.588 \\
Production & $9 \times .091=$ & 0.819 \\
Association & $3 \times .087=$ & 0.261 \\
& & 6.734 \\
\hline
\end{tabular}

After I assigned all of the scores, I multiplied each by the normalized score from table 3 or 4 that was calculated for it.

Then, referring back to figure 1 , I can create a data point for this book with a horizontal coordinate of 6.713 and a vertical coordinate of 6.734 .

\section{Using the Template to Prioritize Preservation Decisions}

Where books are plotted within the framework can begin to assist staff members with setting preservation priorities. As a given book's total physical and contextual score is plotted as a data point, the score falls into one of the nine zones within the framework. A point that is in the "high" zone for both dimensions would be of the highest priority for item-level preservation, while one that falls into a "low" classification for both dimensions would be one of the lowest priorities. In addition, high/high scores would precede medium/high or low/high, medium/high would precede medium/medium or medium/low, and so forth. The data point that resulted from scoring the 1478 copy of Seneca's works, described in the previous section, places the book in the high/high zone of the framework. And while placing an incunabulum as high priority for physical preservation would hardly be surprising, this method provides a less subjective way of doing so, with potentially more justification for our actions.

Although the nine-zone division establishes a general hierarchy, I recognize that a challenge exists in comparing two books with scores that place them in the same zone, or two that fall in the medium/high and high/medium zones, respectively, or high/low and medium/medium. Because physical characteristics received a cumulatively higher allotment of tokens by the experts, I believe that, for the purposes of "breaking a tie," physical characteristics could be weighted more heavily. A book that received a cumulative score of nine for physicality and zero for contextual characteristics would be prioritized more highly than a book receiving a contextual score of nine and physical score of zero.

I established an additional guideline for further fine-tuning of priorities, based on an ordering of the criteria. Based on the allotment of tokens in the second part of 
the survey, the list of terms can be divided into three distinct groups. In figure 2, I listed the criteria in decreasing order, according to their cumulative allocation of tokens. Within that ordering, the characteristics seem to cluster in three groups with similar allocations, and two lines could be drawn to group the criteria. Group One, which received the highest cumulative allocation of tokens, consists of authenticity, historical value, condition, and cultural value. Group Two contains aesthetic value, provenance, availability, special features, and binding; and Group Three has textual variants, demand, value of materials, production, and association. Once a data point is assigned to a given book, a book possessing the criteria in Group One could be considered before those in Group Two or Three. If necessary, the process could continue to be refined on the basis of individual criteria and their respective weights.

\section{Implications for Digitization}

Some collection materials may be more useful as containers of textual information than as inherently valuable objects; and, in some cases, we may determine that dedicating resources to the preservation of the original is not the best use of our resources. Institutional funding for preservation of physical objects has suffered in recent years in favor of digitization projects. ${ }^{8}$ However, digitization can also be a viable preservation strategy under the right circumstances. In keeping with the shift in practice, the framework presented above not only guides physical preservation decisions but also supports the use of surrogates in cases where the information contained within the book would not be lost.

If it can be determined that a given book possesses textual information but little or no physical or contextual information, a digital surrogate may be sufficient. Books that receive extremely low values for a significant number of criteria might be appropriate for substitution with reproductions. These books would likely be located in the low/low section of the framework, with cumulative scores of 3.33 or below for both their physical and contextual attributes. Or perhaps books that do not possess the most highly weighted criteria would be appropriate for digitization. A book in poor condition with no evidence of authenticity or historical value may not require preservation in its physical form. Conversely, substituting a representation for a rare book that possesses many of the 14 criteria may not be sufficient for maintaining the information contained within the object. In this way, my framework has the potential for not only setting priorities among the books in the collection that should be preserved in their physical form, but it also has the potential for indicating which books may be suitable for conversion to other formats.

8. Brian J. Baird, "Consortial Preservation Management: A New Model for Library Preservation Administration," College and Research Libraries News 63.8 (2002): 572-74; Cloonan, "W(h)ither Preservation?" 


\section{Future Refinement of the Framework}

This framework provides one step toward establishing a point of commonality for preservation management in rare book collections; but development of an ironclad model is unlikely, and many issues remain unresolved. For example, as one of the participants suggested, are there any instances when research value would not be incorporated into either the text or another characteristic and would need to be scored separately? Or are there other criteria that should be added or removed as the nature of our collections and the objects we value change over time?

The psychology of emotional responses tied to the intangible qualities of rare books also remains an open issue-one that inevitably affects the scoring process in the framework. Cultural value is one of the included criteria, but when assigning a value to that characteristic, whose definition of cultural value should be used? Valuation of collection materials is very much a social construct and can change dramatically according to the culture in which the object is maintained.

In spite of the improbability of ever completely eliminating subjectivity in preservation decision-making, this framework allows those of us faced with difficult choices in preservation management to establish a starting point upon which everyone can build, with a consistent understanding of applications and potential results.

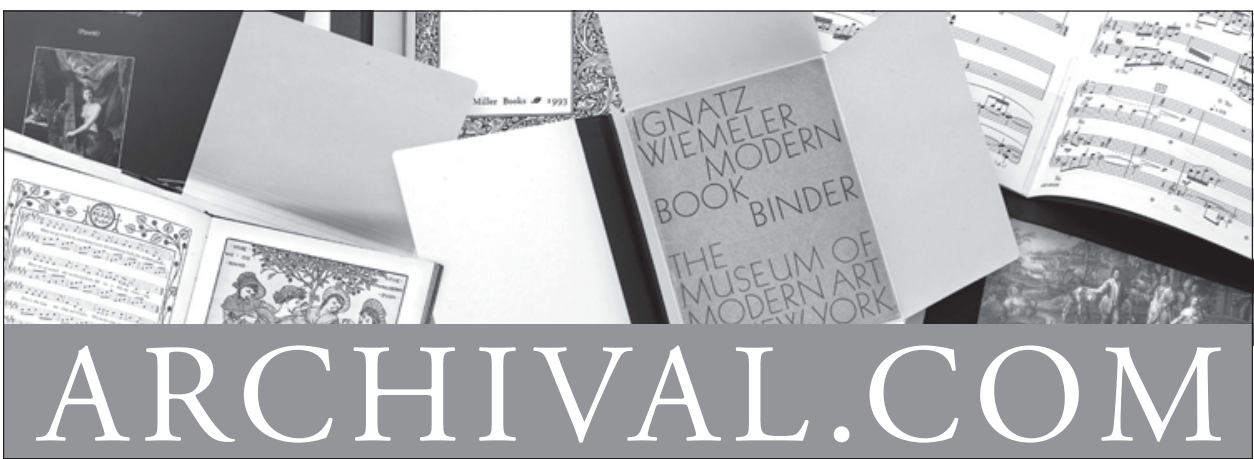

\section{INNOVATIVE SOLUTIONS FOR PRESERVATION}

Call for a complete catalog

Pamphlet Binders

Music Binders

Archival Folders

Manuscript Folders

Hinge Board Covers

Academy Folders

Newspaper/Map Folders

Bound Four Flap

Enclosures

Archival Binders
Polypropylene Sheet \& Photo Protectors Archival Boards Adhesives Bookkeeper Century Boxes Conservation Cloths Non-Glare Polypropylene Book Covers

CoLibri Book Cover System
ARCHIVAL PRODUCTS

P.O. Box 1413

Des Moines, Iowa 50306-1413

Phone: 800.526.5640

Fax: 888.220.2397

E-mail: custserv@archival.com Web: archival.com 